\title{
Temperature and Location of Hot Spots Variation with Spacing in a Vertical Parallel Plate Channel: Conjugate View
}

\author{
Mohammad Samee A.D. ${ }^{*}$, Asif Afzal², Abdul Razak ${ }^{2}$, Ramis M.K. ${ }^{2^{*}}$ \\ ${ }^{1}$ Department of Mechanical Engineering, N. K. Orchid College of Engineering and Technology, Solapur 413002, Maharashtra, \\ India \\ ${ }^{2}$ Department of Mechanical Engineering, P. A. College of Engineering, Visvesvaraya Technological University, Belagavi, \\ Mangaluru 574153, India
}

Corresponding Author Email: ramismk@ pace.edu.in

https://doi.org/10.18280/ijht.370119

Received: 4 May 2018

Accepted: 30 September 2018

\section{Keywords:}

conjugate heat transfer, hot spots, optimum spacing, nuclear elements

\begin{abstract}
The objective of present investigation is twofold, one to determine the effect of operational parameter on maximum temperature (Hot spots temperature) in heat generating (uniform and non-uniform) vertical parallel plates and two is to find out the position of maximum temperature (hot spots location) when plates are placed apart at optimum spacing $\left(B_{\text {opt }}\right)$. A conjugate two dimensional laminar forced convection analysis is carried out in which the equations regulating the heat and fluid flow are solved by using finite difference numerical technique and the obtained algebraic equations are solved by using Thomas algorithm. The parameters viz Reynolds Number $\left(R_{H}\right)$, Conduction-Convection parameter $\left(N_{c c}\right)$, Heat generation parameter $\left(Q_{t}\right)$, and Prandtl Number $\left(P_{r}\right)$, Spacing between the plates $(B)$ were considered for present study, while the aspect ratio $\left(A_{r}\right)$ of the plate is kept constant. The major outcome of present study says that the location of hot spot is mainly affected by $\operatorname{Re}_{H}$ and mode of heat generation (uniform and non-uniform). It is also found that the spacing between the plates $(B), R e_{H}, P_{r}$ and $N_{c c}$ play a major role in reducing the hotspots temperature.
\end{abstract}

\section{INTRODUCTION}

For efficient performance of nuclear reactor it is very important to control the temperature rise in the fuel element within the safe limit. Failing to control the temperature rise in the fuel element may lead to failure of nuclear reactor or unavoidable nuclear accidents. Hence it is important to locate the position of maximum temperature points in the fuel element as it plays an important role in the design of nuclear fuel element [1]. The temperature variation in the fuel element is maximum in radial direction and maximum temperature is located at the center (mid height) of the fuel element $[1,2]$. Considering these important factors it is necessary to control and locate the maximum temperature in the fuel element so as to avoid the adverse condition of reactor core. One such study related to Nuclear fuel element has been reported by Ramis M.K. et al. in which conjugate conduction forced convection of single nuclear fuel element subjected to external flow of liquid sodium as coolant is reported [3]. In another study, Ramis M.K et al. has reported about the comparative study about uniform and non-uniform heat generation in fuel element and concluded that the heat dissipation is more in realistic non-uniform heat generation compare to idealistic uniform heat generation case [4].

Bar-Cohen and Rohsenow has reported about the symmetric and asymmetric heating of vertical parallel plates with constant heat flux and temperature boundary condition under natural convection flow regime [5]. Anand et al. presented a problem of optimal spacing in a vertical parallel plate channel considering the effect of asymmetric heating with natural convection flow of fluid [6]. Bejan and Sciubba studied about the effect of different parameters on optimal spacing between the parallel plates subjected to forced convection cooling [7]. Bello-Ochende and Bejan conducted a mixed convection study with prime objective of optimal spacing in the stack of heated parallel plates placed horizontally [8]. An optimal spacing correlation is developed to fill the gap between forced and free convection. In one more study reported by Bejan and Ledezma an optimal solution is given for arranging the heat generating electric sources placed in a channel [9]. The study further suggests that the pumping power required for cooling purpose can be reduced by maintaining the optimal contact area. Fowler et al. has developed a correlation for optimally placing the staggered parallel plates in forced convection flow of fluid where maximum heat transfer may be achieved [10]. Morrone et al. numerically investigated about the problem of optimal spacing in case of symmetrically heated plates subjected to constant heat flux condition with free convection flow of air [11]. It is finally stated that the Grashofs number and mass flow rate of air plays vital role in optimal spacing.

Morega et al. investigated about the optimal spacing between the stack of parallel plates such that the resistance to flow of heat is minimum under forced convection flow regime [12]. Chen et al. experimentally suggested that the conventional method of placing the electrically heated obstacles at equally spaced distance in a channel subjected to forced convection flow is not convenient for maximum heat transfer [13]. Silva et al. conducted a numerical analysis for optimal placement of discretely heated heat sources on the wall of a channel exposed to forced convection flow of air [14] From the investigation they suggested that the temperature of hot spots can be reduced by increasing the thermal 
conductivity between walls of the channel and heat sources. Sun et al. addressed a numerical problem pertinent to optimal spacing in an array of isothermal plates subjected to mixed convection flow of air with laminar, incompressible flow condition [15]. It is concluded that the value of optimal spacing is less in case of mixed convection compare to forced convection. Rao et al. numerically suggested a correlation for maximum temperature in the walls of a vertical channel mounted with heat generating obstacles with effect of radiation under laminar, incompressible mixed flow condition [16]. Londhe et al. carried out a numerical study under conjugate mixed convection flow of air in a vertical channel mounted with discretely heated heat sources by considering the effects of radiation [17]. It is concluded that the radiation effects cannot be neglected in all the regimes of mixed convection.

Durgam has illustrated a study related to conjugate mixed convection heat transfer analysis for optimal arrangement of heat sources placed in a horizontal channel [18]. The experimental results are validated with numerical results obtained by COMSOL multi-physics 4.3 version package. Apart from this there are many studies available which speaks about the behavior of vertical parallel plates subjected to flow of fluid under forced and mixed convection flow regime [1923]. Recently Samee et al. have investigated numerically about effect of Prandtl number on coolant exit temperature flowing through the heat generating parallel plate channel and Li-ion battery cells $[24,25]$.

It is clear from the above illustrated literature that, the investigation carried out were focused on the optimal spacing problems related to the arrangements of heat generating sources placed in a channel (Vertical/horizontal) or stack of heated plates subjected to forced, free and mixed convection flow regime with or without considering the conjugate condition [5-18]. Numerical studies reported by the Ramis et al. were associated with single heat generating plate subjected to forced convection flow of coolant under conjugate, laminar, incompressible flow condition [3, 4]. Whereas the study reported by Samee et al. is pertinent to heat generating parallel plates but considered only the effect of Prandtl number on exit temperature of coolants [24].

Considering some of the above stated facts and elements the prime objective of present investigation is to determine the effect of channel spacing $(B)$ on maximum temperature in heat generating vertical parallel plates and to find out the location of hotspots in the plates when the plates are kept at optimal spacing $\left(B_{\text {opt }}\right)$. The conjugate numerical analysis is conducted for volumetric heat generating plates subjected to flow of different coolants liquid $\operatorname{sodium}\left(P_{r}=0.005\right)$, Sodium$\operatorname{potassium}\left(P_{r}=0.00753\right), \quad$ Lead $\quad\left(P_{r}=0.02252\right), \quad$ Helium $\left(P_{r}=0.666\right)$ and effect of parameters like $R e_{H}, N_{c c}$, and $Q_{t}$, keeping constant aspect ratio $\left(A_{r}\right)$ of the plates is also specified.

\section{MATHEMATICAL FORMULATION}

The Figure 1(a) shows the physical model of present stated problem consisting of volumetric heat generating vertical parallel plates kept apart at spacing $(2 B)$. The fluid is made to flow through the space available between the plates. The coolant enters the channel with uniform temperature $T_{\infty}$ and uniform velocity $U_{\infty}$ and exit from the trailing edge of the plates. When the flowing fluid enters the channel it carries away the heat from the lateral surface of the vertical plates due to interaction between the heat generating solid domain and heat carrying fluid domain and the heat transfer phenomenon occurs at the interface of two domains.
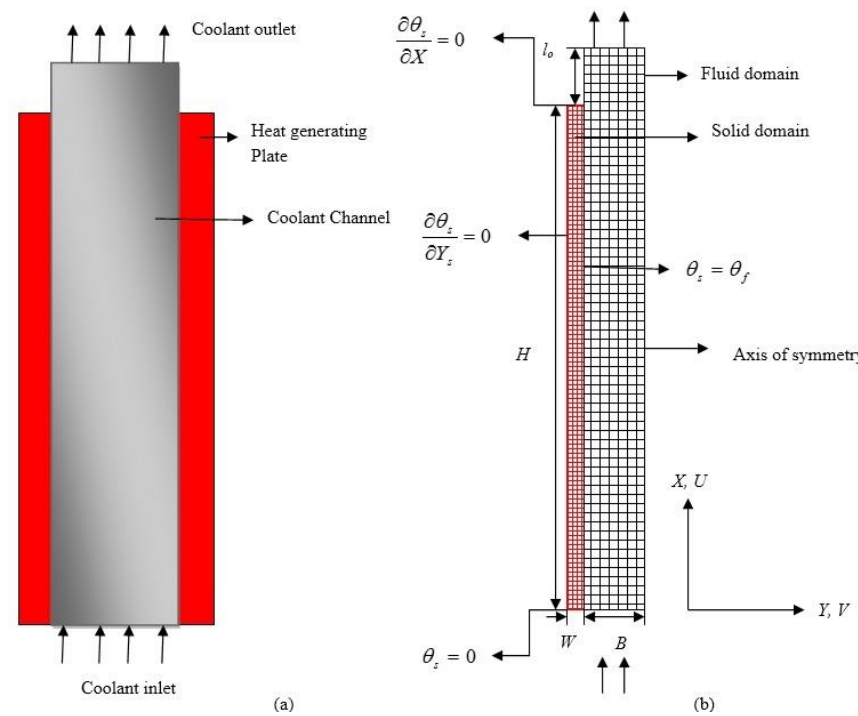

Figure 1. (a) Physical model, (b) Computational model

Figure 1(b) shows the computational domain of the present problem let the thickness of each plate be $W$, and thickness of fluid domain be $B$, as symmetry is considered at the center of the channel due to constant rate of heat generation from both the plates and to avoid the loss of computational time and cost. $H$ is the height of each plate, $l_{o}$ is the extended domain of the fluid (the extra fluid domain is added to catch the approximate outflow boundary conditions of flowing fluid) from the trailing edge of the plate. It is assumed that the leading edge of the plate is maintained at coolant free stream temperature $T_{\infty}$, the rate at which energy dissipated from trailing edge is considered to be negligible. To satisfy the conjugate condition at the interface of solid and fluid domain the continuity of temperature and heat flux is assumed which is shown in the Figure 1 (b).

The above described conjugate heat transfer problem can be achieved numerically with ease but without sacrificing its much of physics, the following simplifying approximations and assumptions are introduced additionally:

(i) The plate material is isotropic and homogeneous.

(ii) The plate thermal conductivity is independent of temperature.

(iii) The conjugate heat transfer problem is steady and two dimensional.

(iv) The Newtonian coolant flow between the parallel plates is laminar, viscous and incompressible.

(v) The coolants thermo-physical properties are constant.

Taking into consideration of the approximations and assumptions stated above, the equations governing the steady state temperature distribution in the plate having non-uniform volumetric energy generation can be obtained in its dimensionless form as

$\frac{\partial^{2} \theta_{S}}{\partial X^{2}}+C \frac{\partial^{2} \theta_{S}}{\partial Y_{S}^{2}}+C Q(X)=0$

where, $\theta_{s}$ stand for temperature in the plate and $C$ is a constant related to aspect ratio of the plate. The function $Q(X)$ in the source term is a cosine function of the axial coordinate $X$ and can be expressed as [26]. 
$Q(X)=Q_{\max } \operatorname{Cos} \pi\left(\frac{1}{2}-X\right)$

Since the volumetric energy generation in the plate is nonuniform, an appropriate parameter based on total energy generated within each plate is defined, which is termed as 'total energy generation parameter' $Q_{t}$. The value of $Q_{t}$ is essentially obtained by integrating the volumetric energy generation function $Q(X)$ over the entire volume of each plate which yields an expression in terms of maximum value of volumetric energy generation function $Q_{\max }$. The parameter $Q_{t}$ is expressed as:

$$
Q_{t}=\frac{2}{\pi} Q_{\max }
$$

Keeping in mind the plate part of the solution domain as mentioned earlier in this section, the solution of Eq. (1) can be obtained by imposing the following most appropriate boundary conditions:

$$
\begin{aligned}
& Y_{s}=-1 ; 0 \leq X \leq 1, \frac{\partial \theta_{s}}{\partial Y_{s}}=0 \\
& Y_{s}=0 ; 0 \leq X \leq 1, \quad \theta_{s}=\theta_{f} \\
& X=0 ;-1 \leq Y_{s} \leq 0, \theta_{s}=0 \\
& X=1 ;-1 \leq Y_{s} \leq 0, \frac{\partial \theta_{s}}{\partial X}=0
\end{aligned}
$$

Employing stream function-vorticity formulation and invoking appropriate approximations and assumptions, the equations governing the flow and thermal fields in the channel formed by two adjacent parallel plates can be obtained in their dimensionless form as

Stream-Function: $\frac{\partial^{2} \Psi}{\partial X^{2}}+\frac{\partial^{2} \Psi}{\partial Y_{f}^{2}}=-\Omega$

Vorticity-Transport:

$U \frac{\partial \Omega}{\partial X}+V \frac{\partial \Omega}{\partial Y_{f}}=\frac{1}{R e_{H}}\left(\frac{\partial^{2} \Omega}{\partial X^{2}}+\frac{\partial^{2} \Omega}{\partial Y_{f}^{2}}\right)$

Energy: $U \frac{\partial \theta_{f}}{\partial X}+V \frac{\partial \theta_{f}}{\partial Y_{f}}=\frac{1}{R e_{H} P r\left(\frac{\partial^{2} \theta_{f}}{\left.\partial X^{2}+\frac{\partial^{2} \theta_{f}}{\partial Y_{f}{ }^{2}}\right)}\right.}$

Eqns. (5)-(7) can be solved by imposing physical conditions all along the boundaries of the flow and thermal fields in the channel. However, in the present study, in order to impose physically meaningful conditions at the boundary corresponding to the outlet of the channel, the actual outflow boundary of the flow and thermal fields are located further downstream at a distance $L_{o}$ from the trailing edge of the plate. As the flow and thermal fields in the channel is expected to be symmetric about its vertical central line, the computational fluid domain considered in the present study is also corresponding to the half of the channel and thus, the conditions of symmetry of flow and thermal fields can be imposed on this line of symmetry. The boundary conditions suited to the present conjugate heat transfer study can be presented in dimensionless form as

$$
\begin{aligned}
& Y_{f}=0 ; 0 \leq X \leq 1, \quad \Psi=0, \quad \Omega=-\frac{\partial^{2} \Psi}{\partial Y_{f}^{2}} \\
& \frac{\partial \theta_{f}}{\partial Y_{f}}=\frac{1}{N_{c c}} \frac{\partial \theta_{s}}{\partial Y_{s}} \\
& Y_{f}=0 ; 1<X \leq\left(1+L_{o}\right), \Psi=0, \Omega=0, \frac{\partial \theta_{f}}{\partial Y_{f}}=0 \\
& Y_{f}=B ; 0 \leq X \leq\left(1+L_{o}\right), \Psi=\Psi_{b}, \Omega=0, \frac{\partial \theta_{f}}{\partial Y_{f}}=0 \\
& X=0 ; 0 \leq Y_{f} \leq B, \quad \frac{\partial \Psi}{\partial X}=0, \Omega=0, \theta_{f}=0 \\
& X=\left(1+L_{o}\right) ; \quad 0 \leq Y_{f} \leq B, \frac{\partial \Psi}{\partial X}=0, \frac{\partial \Omega}{\partial X}=0, \frac{\partial \theta_{f}}{\partial X}=0
\end{aligned}
$$

The dimensionless variables and parameters used in Equations (1)-(8) are defined as

$$
\begin{aligned}
& X=\frac{x}{H} \quad Y_{s}=\frac{y}{W} Y_{f}=\frac{y}{H} \quad U=\frac{u}{U_{\infty}} \\
& V=\frac{v}{U_{\infty}} \theta=\frac{T-T_{\infty}}{T_{0}-T_{\infty}} \\
& A_{r}=\frac{H}{2 W} B=\frac{b}{H} L_{o}=\frac{\ell_{o}}{H} \\
& Q(X)=\frac{q^{\prime \prime \prime}(x) W^{2}}{k_{s}\left(T_{0}-T_{\infty}\right)} Q_{\max }=\frac{q_{\max }^{\prime \prime \prime} W^{2}}{k_{s}\left(T_{0}-T_{\infty}\right)} N_{c c}=\frac{k_{f}}{k_{s}}\left[\frac{W}{H}\right], \\
& \operatorname{Re}_{H}=\frac{U_{\infty} H}{v}
\end{aligned}
$$

Eq. (1) used for the temperature distribution in the plate and Eqns. (5)-(7) for the flow and thermal fields in the coolant flowing through the channel are coupled and therefore, the solutions of these equations have to be obtained simultaneously by employing appropriate numerical schemes and an iterative solution procedure.

\section{NUMERICAL METHOD}

Eq. (1) governing the temperature distribution in the plate, Eqns. (5) and (6) governing the flow field in the coolant, and Eq. (7) representing the thermal field in the coolant, the equations being coupled, are solved simultaneously by employing finite difference schemes in conjunction with an iterative solution procedure and by satisfying the conditions of continuity of temperature and heat flux at the solid-fluid interface. Accordingly, equation (1) together with its boundary conditions given in Eq. (4), and Eq. (5) along with its boundary conditions specified in equation (8) are discretized using second-order accurate finite difference schemes and the resulting system of linear algebraic equations are solved using 'Thomas Algorithm' and by employing 'Line-by-Line GaussSeidel' iterative solution procedure. On other side, the pseudotransient form of Eqns. (6) and (7) along with their boundary conditions presented in Eq. (8) are discretized using Alternating Direction Implicit (ADI) scheme and the resulting system of finite difference equations are solved using 'Thomas Algorithm'. The computer code validation and grid independence test are explained in detail in [29-31]. 


\section{RESULTS AND DISCUSSIONS}

The prime aim of the present numerical study is to find the effect of different thermal and fluid flow parameters on maximum temperature (hotspots temperature) and location of hot spots (maximum temperature) in a vertical parallel nuclear fuel elements subjected to flow of different coolants such as Liquid Sodium, Liquid Sodium-Potassium, Liquid Lead and Helium gas, having Prandtl number 0.005, 0.00753, 0.02252, and 0.666 respectively. Finite difference scheme is used to solve the governing equations of solid and fluid domain, Pseudo transient equations are solved by using ADI (Alternating direction implicit) technique. The following results were obtained for the effect of parameters like Prandtl number $\left(P_{r}\right)$, Reynolds number $\left(R e_{H}\right)$, Conduction convection parameter $\left(N_{c c}\right)$, Heat generation parameter $\left(Q_{t}\right)$, spacing between the plates $(B)$ and optimal spacing $\left(B_{\text {opt }}\right)$ on location of hot spots $\left(H_{s p o t}\right)$ and hot spots temperature $\left(\theta_{\max }\right)$ in vertical parallel plates keeping the aspect ratio $\left(A_{r}\right)$ of plate constant.

\subsection{Effect of $N_{c c}$ on $\theta_{\max }$}

Figure 2 elucidate the effect of $N_{c c}$ on maximum temperature $\left(\theta_{\max }\right)$ in the fuel element for different coolants when the parameters like $R e_{H}=1000, Q_{t}=0.4$, and $A_{r}=10$ are kept constant. It is observed that with increase in the value of $N_{c c}$ the maximum temperature in the fuel element decreases, this may be attributed to fact that with increase in the $N_{c c}$ the conductivity of coolant increases and of fuel element decreases hence the temperature in the fuel element drops drastically. The range by which the maximum temperature in the fuel element drops is more for the liquid sodium coolant compare to other coolants. But for helium as a coolant it is seen that the maximum temperature in the fuel element is less as compare to the case of other coolants.

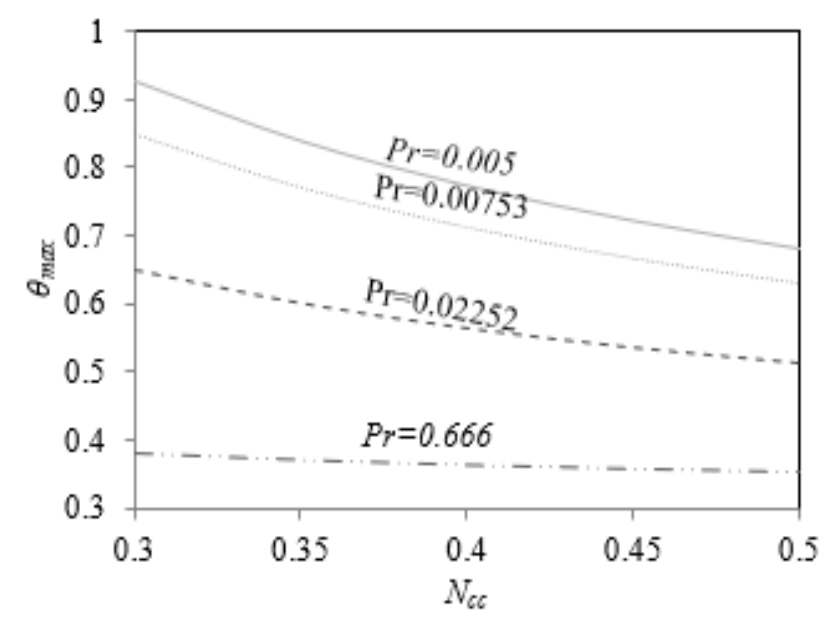

Figure 2. Conduction-convection parameter $\left(N_{c c}\right) V s$ maximum temperature $\left(\theta_{\max }\right)$ for different coolants

\subsection{Effect of $Q_{t}$ on $\theta_{\max }$}

The Figure 3 depicts the effect of heat generation $\left(Q_{t}\right)$ on maximum temperature $\left(\theta_{\max }\right)$ in the plate for different coolants, liquid sodium, sodium potassium, lead and helium while other parameters like $A_{r}=10, R e_{H}=1000$, and $N_{c c}=0.4$ are kept constant. It is clear from the figure that with increase in the heat generation $\left(Q_{t}\right)$ the maximum temperature within the fuel element also increases. It is also observed that under conjugate phenomenon for coolant like liquid sodium the rise in the temperature of fuel element is more compare to the other coolants considered in the present investigation. It means that the ability to conduct the heat from the fuel element by the coolant is poor when the heat generation rate is high. It is further observed that since the spacing between the plates for each coolant remains same hence the convective heat transfer coefficient remains constant which may affect the coolants cooling ability.

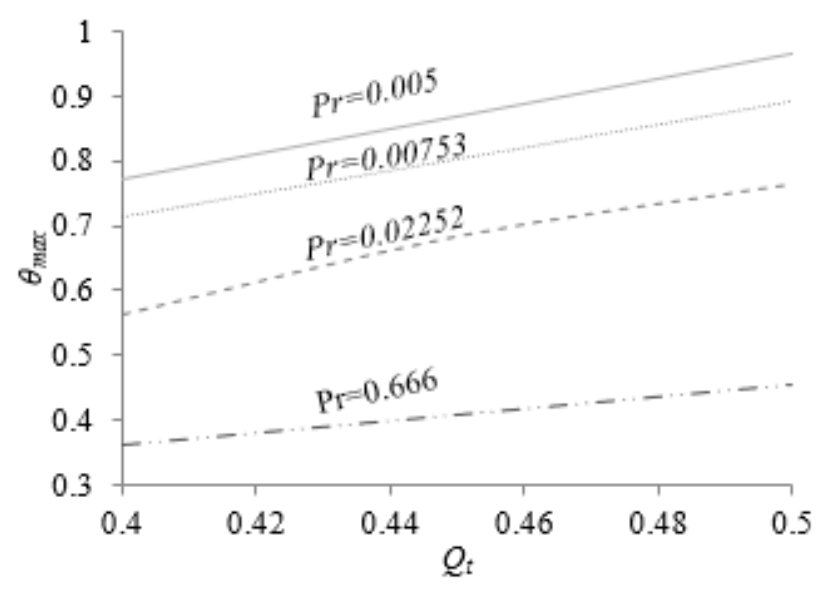

Figure 3. Total Heat Generation $\left(Q_{t}\right) V s$ Maximum Temperature $\left(\theta_{\max }\right)$ for different coolants

\subsection{Effect of $B$ on $\theta_{\max }$}

Figures 4-7, illustrates the effect of $\operatorname{spacing}(B)$ between the heat generating plates on maximum temperature $\left(\theta_{\max }\right)$ in the plates for different coolants, liquid sodium, sodium-potassium, lead and helium respectively when the parameters $A_{r}=10$, $N_{c c}=0.4$, and $Q_{t}=0.4$ are kept constant. It is observed from the trend of the figures that with increase in the spacing between the plates the maximum temperature decreases which is as usual expected. The prime reason for such trend may be attributed to the fact that with increase in the spacing between the plates the quantity of fluid flowing also get increased which may tend to carry away the more amount of heat from the surface of the plates hence drop in the maximum temperature is observed.

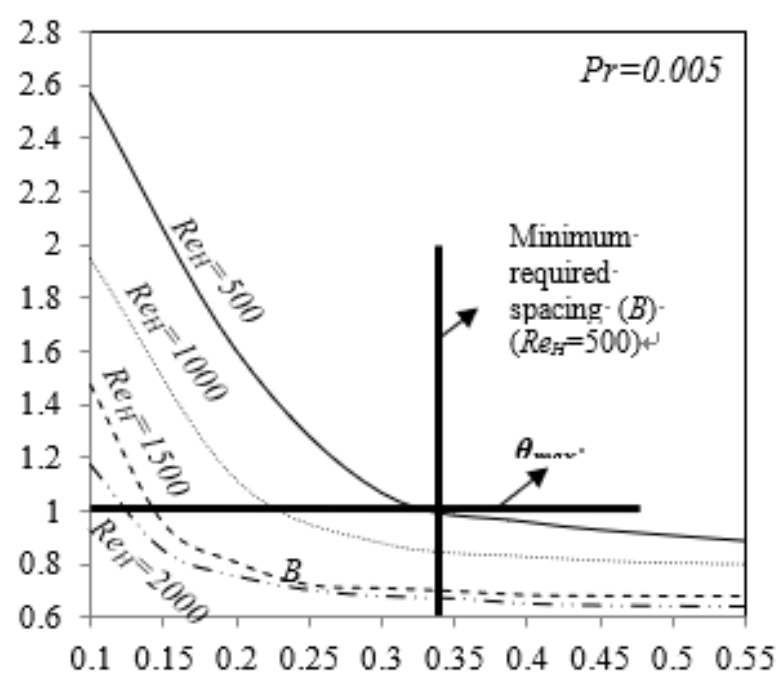

Figure 4. Spacing $(B) V s$ Maximum temperature $\left(\theta_{\max }\right)$ 


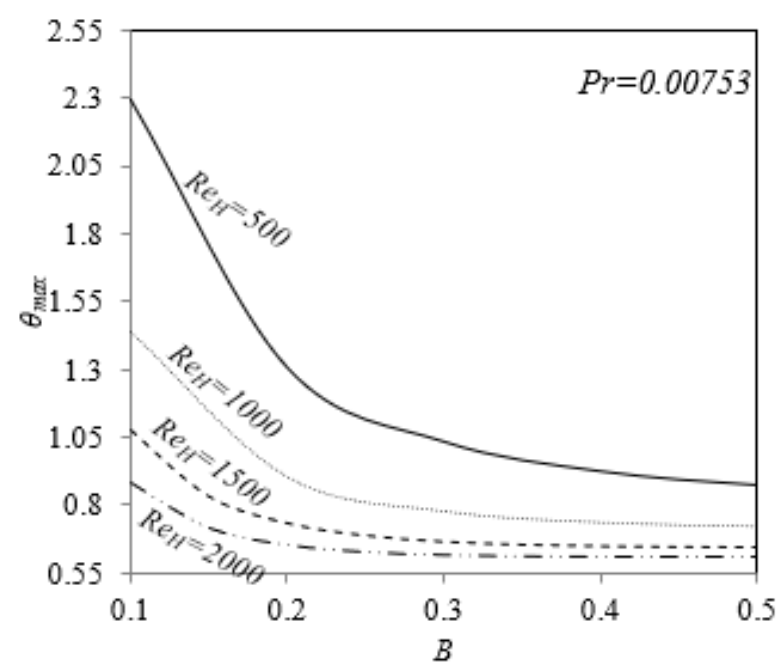

Figure 5. Spacing $(B) V s$ Maximum temperature $\left(\theta_{\max }\right)$

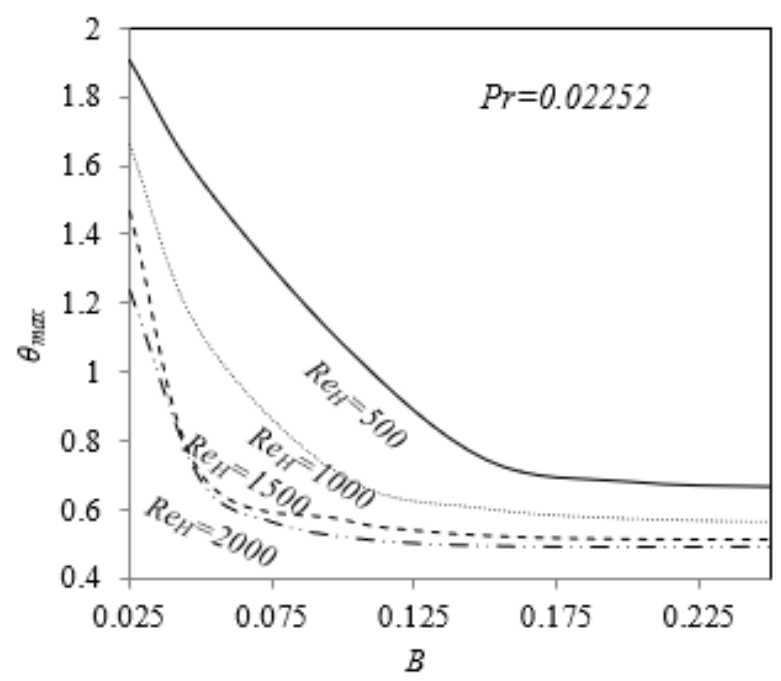

Figure 6. Spacing $(B) V s$ Maximum Temperature $\left(\theta_{\max }\right)$

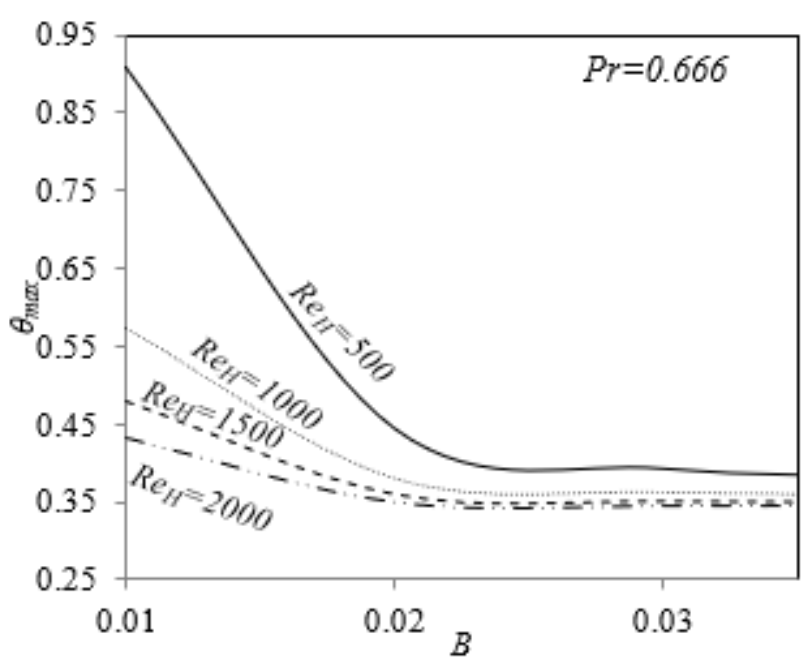

Figure 7. Spacing $(B) V s$ Maximum temperature $\left(\theta_{\max }\right)$

It is also observed that with increase in the $R e_{H}$ the maximum temperature decreases as the higher $R e_{H}$ creates more convection in the fluid. The following observations are made from the Figures 4-7.

- The spacing $(B)$ required between the heat generating plates under conjugate condition for the case of liquid metal coolants is more compare to gas coolant.

- In each case of liquid metal coolant there exists the minimum value of spacing $(B)$ below which the maximum temperature within the fuel element crosses its safer limit.

\subsection{Effect of $\operatorname{Re}_{H}$ on $H_{\text {spot }}$}

Figure 8 illustrate the effect of $R e_{H}$ on hotspot location with non-uniform heat generation in plates when other parameters like $A_{r}=10, Q_{t}=0.4$, and $N_{c c}=0.4$ are being kept constant for different coolants. From the Figure it is clear that with increase in $R e_{H}$ the hotspot drift upward (for $P r=0.005 \& \operatorname{Pr}=0.00753$ ) in fuel element, This is mainly due to increase in thermal dissipation rate from the lateral surface of fuel element at low $\mathrm{Pr}$ which increases the quantity of heat carried by the coolant and also leads to increase the amount of coolant flowing between the plates, as at low $\mathrm{Pr}$ the Spacing is more. On the other hand it can be said that with increase in $R e_{H}$ the hotspot drift downwards (for $\operatorname{Pr}=0.02252$ and $P r=0.666$ ) this is mainly due to decrease in the rate of heat dissipation from the surface of the plate at high Pr. Further it can be said that with increase in $\operatorname{Pr}$ the spacing between the plates reduces.

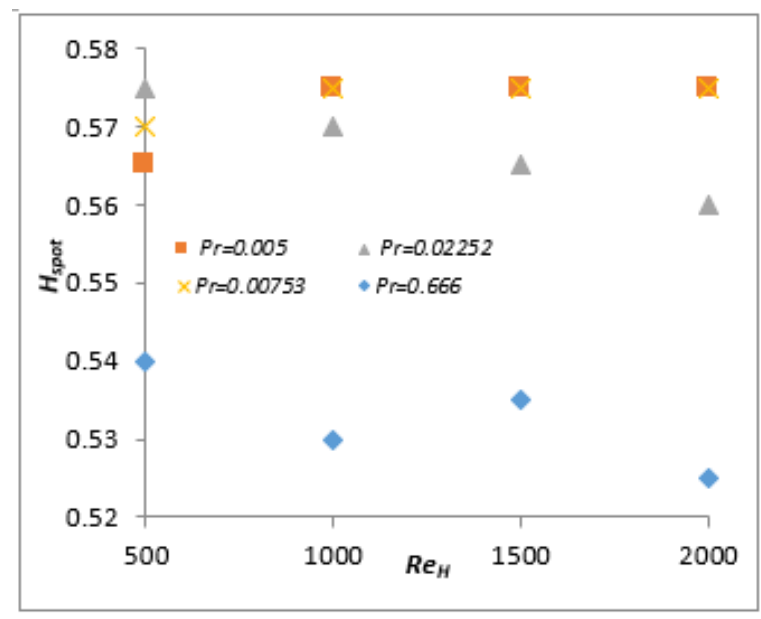

Figure 8. Reynolds Number $\left(\operatorname{Re}_{H}\right)$ Vs Hot Spot Location $\left(H_{\text {spot }}\right)$ with non-uniform heat generation in plates

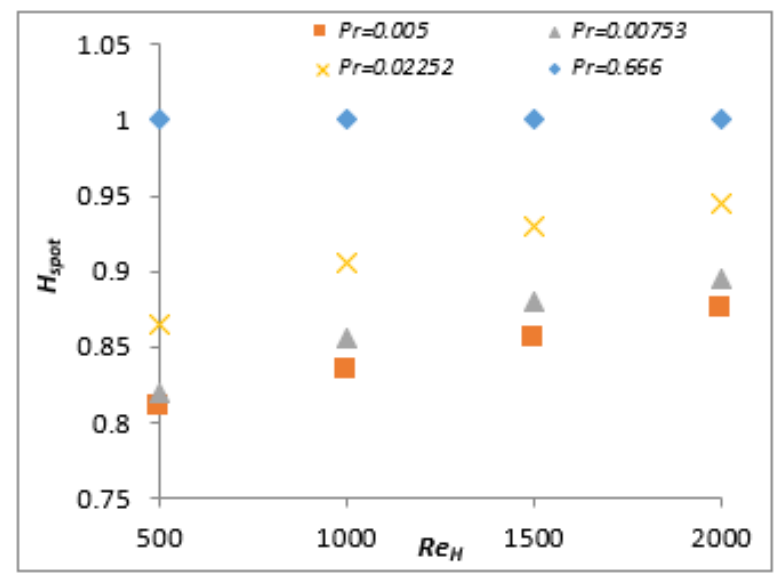

Figure 9. Reynolds Number $\left(R e_{H}\right)$ Vs Hot Spot Location $\left(H_{\text {spot }}\right)$ with uniform heat generation in plates

Figure 9 depicts the effect of $R e_{H}$ on hotspot location with uniform heat generation in the plates when $Q_{t}=0.4, A_{r}=10$ and $N_{c c}=0.4$ are kept constant for different coolants. From the Figure we can say that with increase in $R e_{H}$ the hot spot drift 
upwards in the plate (for $\operatorname{Pr}=0.005,0.00753$ and 0.666 ) which is due to fact that at low Prandtl values the heat dissipation from the surface of the plate increases and the space between the plates also increases which allows more amount of coolant to flow further increases the amount of heat carried. But it is also found that at high $\operatorname{Pr}$ value the location of hotspot almost remains constant without any drift, this may be due to decrease in spacing between the plate allowing less coolant to flow and also plates become too closer to each other which leads to resist the flow of heat, hence maximum heat will get accumulated at one fixed location. It is worth to note here that the uniform heat generation rate also plays an important role in the location of hotspots.

\subsection{Effect of $\mathrm{Nec}$ on $\mathrm{H}_{\text {spot }}$}

Figure 10 shows the effect of $N_{c c}$ on hotspot location in fuel element with nonuniform heat generation for different coolants keeping $\operatorname{Re}_{H}=1000, Q_{t}=0.4$ and $A_{r}=10$ constant. From figure it can be said that with increase in the value of $N_{c c}$ the location of hotspot in fuel element move downward side, this may be due to increase in the heat conductivity of coolant as the coolant is able to take away more amount of heat from the fuel element and also the spacing between the plate is fixed, it is also observed that for each coolant the drift in hotspot location is different and this may be due to change in value of $\mathrm{Pr}$, for low $\mathrm{Pr}$ coolants like Sodium and Sodium-Potassium the drift almost remains same where as for higher values of Prandtl number the drift of hotspot changes.

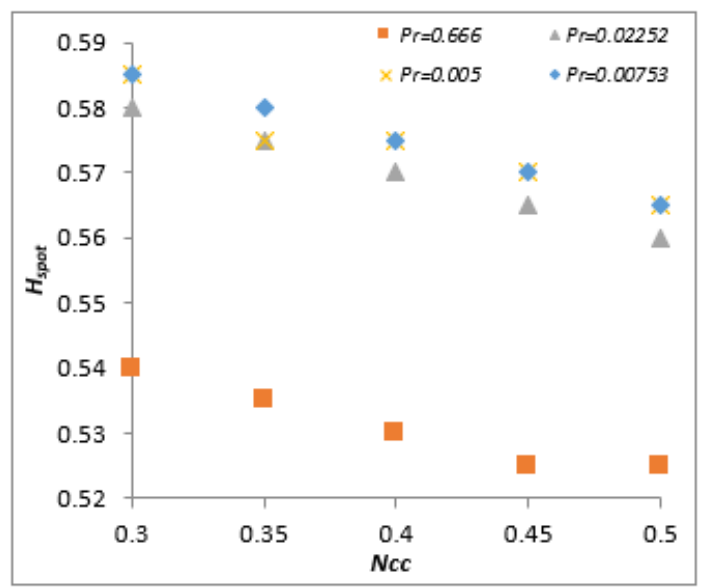

Figure 10. Conduction-Convection Parameter $\left(N_{c c}\right) V s$ Hot Spot Location $\left(H_{s p o t}\right)$ with non-uniform heat generation

Figure 11 depicts the impact of $N_{c c}$ on hotspot location in solid domain generating uniform amount of heat while parameters like $\operatorname{Re}_{H}=1000, Q_{t}=0.4$ and $A_{r}=10$ are kept fixed and plotted for different coolants. It is observed plainly from figure that with increase in the value of $N c c$ there is no change in the location of hotspot. This is due to uniform rate of heat generation from the solid domain and also may be due to constant optimum spacing between the plates. But from the figure it is also seen that for higher values of the Prthe location of hotspot is almost nearer to trailing edge of the plate this may be due to closer spacing between the plates, as most of the heat get accumalated at top ends of plate. It is also observed that with lower $P r$ the hotspot drift downwards away from trialing edge of the plate becuase the space available between the plates is more which allows more fluid to flow thus avoiding the accumalation of heat near trailing edge of the plate.

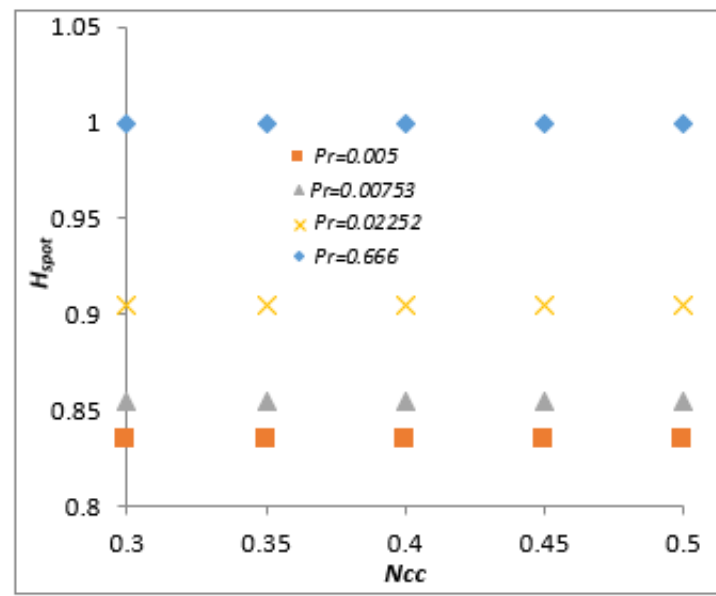

Figure 11. Conduction-Convection $(\mathrm{Ncc}) \mathrm{VsHot}$ Spot Location $\left(H_{\text {spot }}\right)$ with uniform heat generation

\subsection{Effect of $Q t$ on $H_{\text {spot }}$}

Figure 12 shows the impact of $Q_{t}$ on hotspot location having non-uniform energy generation rate for different coolants with constant $\operatorname{Re}_{H}=1000, N_{c c}=0.4$ and $A_{r}=10$. It is clearly observed from Figure that with increase in the rate of heat generation for low Prthere is not much change in the location of hotspot but for higher values of Prhotspot location drift towards leading edge of the plate, this may be due to decrease in spacing between the plate with incresing value of Prthus bringing the plates closer to each other which leads to reduce the volume of coolant flowing between the plates which further affect the ability of coolant to take away the heat from the fuel element hence cause the downward drifting of hotspot towards leading edge of the plate.

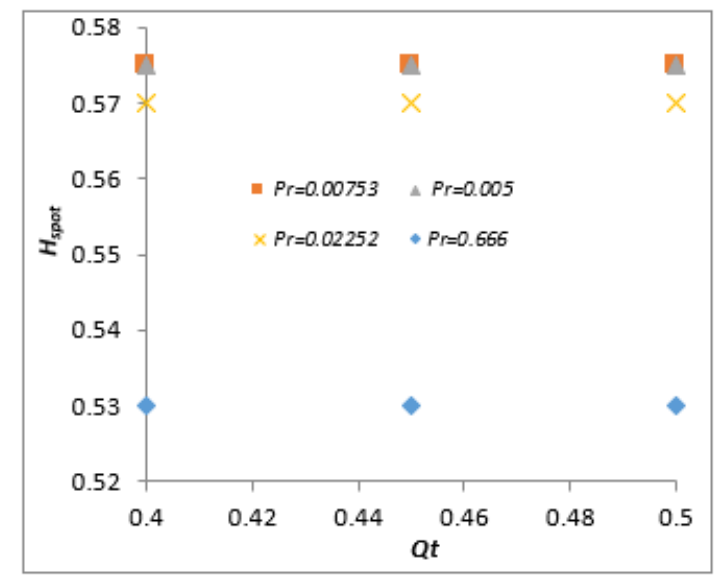

Figure 12. Total Heat Generation Parameter $\left(Q_{t}\right)$ Vs Hot Spot Location $\left(H_{s p o t}\right)$ with non-uniform heat generation

Figure 13 illustrate the effect of $Q_{t}$ on hotspot location having uniform energy generation rate for different coolants while $R e_{H}=1000, A_{r}=10$ and $N_{c c}=0.4$ are kept constant. From the Figure it is clear that with increase in $Q_{t}$ the location of hot spot for each coolant remains constant this may be due to fact that as the rate of heat generation is uniform and for low Prandtl number the location of hotspot is away from the trailing edge while for higher Prandtl number the hotspot location is drifting towards trailing edge of the plate again this is mainly due to spacing available between the plates. For coolant like Lead and Helium the spacing decreases thus 
bringing the two plates near to each other thus allowing the resistant to flow of heat hence accumulating the maximum amount of heat at or near the trailing edge.

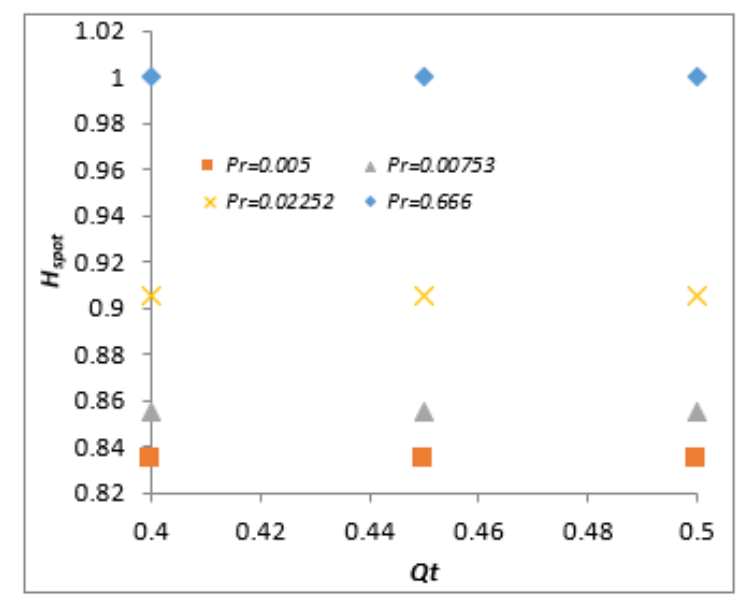

Figure 13. Total Heat Generation Parameter $\left(Q_{t}\right)$ Vs Hot Spot Location $\left(H_{s p o t}\right)$ with uniform heat generation

\section{CONCLUSIONS}

A multidimensional thermal and fluid flow conjugate numerical analysis is carried out for the case of vertical parallel plate channel generating volumetric heat. Forced convection flow of different fluids like Liquid sodium, Liquid sodium-potassium, Liquid Lead, and helium under steady state condition is considered. Parameters like $\operatorname{Re}_{H}, P_{r}, N_{c c}, B$ and $Q_{t}$, when aspect ratio $\left(A_{r}\right)$ of the fuel element is kept fixed will have the major influence on the location of hot spots and hotspots temperature in nuclear fuel element. Form the results obtained the following concluding remarks were made.

- The maximum temperature $\left(\theta_{\max }\right)$ in the plates increases with increase in $Q_{t}$ but decreases with increase in $N_{c c}$ and $B$.

- Hot spot location is greatly influenced by $R e_{H}$ and $P r$.

- In case of non-uniform heat generation the hot spots are located at the mid position of the fuel element and for the case of uniform heat generation the position of hot spots get drifted up in the fuel element.

- Helium as a special case drift the hotspots towards the trailing edge of the plate for uniform heat generation and for non-uniform heat generation the hotspots location drift down from the trailing edge of the plate.

- The coolants with low Pr (Liquid sodium and Sodium potassium) drift the hotspots towards the trailing edge of the plate for the realistic case of non-uniform heat generation.

- Liquid sodium proves to be good coolant for controlling the location and range of maximum temperature (hot spots) in nuclear fuel element.

- There exists a minimum value of spacing between the plates $(B)$ below which the maximum temperature in the fuel element crosses its safer limit.

\section{REFERENCES}

[1] Winterton RHS. (1981). Thermal design of nuclear reactors. Pergamon Press.

[2] Wakil MMEl. (1971). Nuclear heat transport. International Text Book Company, Intext Publisher.
[3] Ramis MK, Jilani G, Jahangeer S. (2008). Conjugate conduction-forced convection heat transfer analysis of a rectangular nuclear fuel element with non-uniform volumetric energy generation. International Journal of Heat and Mass Transfer 51: 517-525. https://doi.org/10.1016/j.ijheatmasstransfer.2007.05.019

[4] Ramis MK, Jilani G. (2010). Heat and fluid flow characteristics of liquid sodium flowing past a nuclear fuel element with non-uniform energy generation. International Journal of Heat and Mass Transfer 53: 1682-1690. https://doi.org/10.1016/j.ijheatmasstransfer.2010.01.021

[5] Bar-Cohen A, Rohsenow WM. (1984). Thermally optimum spacing of vertical, natural convection cooled, Parallel plates. ASME Journal of Heat Transfer 106: 116123. https://doi.org/10.1115/1.3246622

[6] Anand NK, Kim SH, Fletcher LS. (1992). The effect of plate spacing on free convection between heated parallel plates. ASME Jornal of Heat Transfer 114: 515-518. https://doi.org/10.1115/1.2911306

[7] Bejan A, Sciubba E. (1992). The optimal spacing of parallel plates cooled by forced convection. Int J Heat Mass Transfer 35: 3259-3264. https://doi.org/10.1016/0017-9310(92)90213-C

[8] Bello-Ochende T, Bejan A. (2004). Optimal spacing for mixed convection. ASME Journal of Heat Transfer 126: 956-962. https://doi.org/10.1115/1.1833363

[9] Bejan A, Ledezma GA. (1996). Thermodynamic optimization of cooling techniques for electronic packages. Int. J. Heat Mass Transfer 39: 1213-1221. https://doi.org/10.1016/0017-9310(95)00196-4

[10] Fowler AJ, ledezma GA, Bejan A. (1997). Optimal geometric arrangement of staggered plates in forced convection. Int J Heat Mass Transfer 40: 1795-1805. https://doi.org/10.1016/S0017-9310(96)00251-7

[11] Morrone B, Campo A, Manca O. (1997). Optimum plate separation in vertical parallel plate channels for natural convective flows: Incorporation of large spaces at the channel extremes. Int J Heat Mass Transfer 40: 993-1000. https://doi.org/10.1016/0017-9310(96)00197-4

[12] Morega AM, Bejan A, Lee SW. (1995). Free stream cooling of a stack of parallel plates. Int. J. Heat Mass Transfer 38: 519-531. https://doi.org/10.1016/00179310(94)00123-D

[13] Chen S, Liu Y, Chan SF, Liung CW, Chan TL. (2001). Experimental study of optimum spacing problem in the cooling of simulated electronic package. Heat and Mass Transfer 37:

251-257. https://doi.org/10.1007/s002310000168

[14] da Silva AK, Lorente S, Bejan A. (2004). Optimal distribution of discrete heat sources on a plate with laminar forced convection. Int. Journal of Heat and Mass Transfer 47: 2139-2148. https://doi.org/10.1016/j.ijheatmasstransfer.2003.12.009

[15] Sun H, Li R, Chenier E, Lauriat G, Padet J. (2012). Optimal plate spacing for mixed convection from an array of vertical isothermal plates. Int $\mathbf{J}$ of Thermal Sciences $\quad 55$ : 16-30. https://doi.org/10.1016/j.ijthermalsci.2011.12.013

[16] Gururaj Rao C, Balaji C, Venkateshan SP. (2002). Effect of surface radiation on conjugate mixed convection in a vertical channel with discrete heat source in each wall. International journal of Heat and Mass Transfer 45: 3331-3347.
https://doi.org/10.1016/S0017- 
9310(02)00061-3

[17] Londhe SD, Rao CG. (2013), Mixed convection with conduction and surface radiation in vertical channel with discrete heating. J. Inst. Eng. India Ser. C 94: 213-223. https://doi.org/10.1007/s40032-013-0076-y

[18] Durgam S, Venkateshan SP, Sundarajan T. (2017). Experimental and numerical investigations on optimal distribution of heat source array under natural and forced convection in a horizontal channel. Int $\mathbf{J}$ of Thermal Sciences 115: 125-138. https://doi.org/10.1016/j.ijthermalsci.2017.01.017

[19] Mathews RN, Balaji C. (2006). Numerical simulation of conjugate, turbulent mixed convection heat transfer in a vertical channel with discrete heat sources. International Communication in Heat ans Mass Transfer 33: 908-916. https://doi.org/10.1016/j.icheatmasstransfer.2006.02.01 3

[20] Sun H, Li R, Chenier E, Lauriat G, Padet J. (2012). Optimal plate spacing for mixed convection from an array of vertical isothermal plates. International Journal of Thermal Sciences 55: 16-30. https://doi.org/10.1016/j.ijthermalsci.2011.12.013

[21] Kumar Hotta T, Balaji C, Venkateshan SP. (2014). Optimal distribution of discrete heat sources under mixed convection - a heuristic approach. ASME Journal of Heat Transfer 136: 104503-1-104503-7. https://doi.org/10.1115/1.4027350

[22] Turkoglu H, Yucel N. (1995). Mixed convection in vertical channels with discrete heat source. Heat and Mass Transfer 30: 159-166. https://doi.org/10.1007/BF01476525

[23] da Silva AK, Lorente S, Bejan A. (2004), Optimal distribution of discrete heat sources on a plate with laminar forced convection. Int Journal of Heat and Mass Transfer 47: 2139-2148. https://doi.org/10.1016/j.ijheatmasstransfer.2003.12.009

[24] Mohammad Samee AD, Afzal A, Razak A, Ramis MK (2018). Effect of Prandtl number on average exit temperature of coolant in heat generating vertical parallel plate channel: a conjugate analysis. Heat Transfer Asian Research 47(4):

603-619. https://doi.org/10.1002/htj.21330

[25] Afzal A, Mohammed Samee AD, Abdul Razak RK, Ramis MK. (2019). Effect of spacing on thermal performance characteristics of Li-ion battery cells. J Therm Anal Calorim 135: 1797-1811. https://doi.org/10.1007/s10973-018-7664-2

[26] El-Wakil MM. (1962). Nuclear power engineering. McGraw- Hill Book Company, New York, pp. 203-204.

[27] Sparrow M, Chyu MK. (1982), Conjugate forced convection-conduction analysis of heat transfer in a plate fin. ASME Journal of Heat Transfer 104: 204-206. https://doi.org/10.1115/1.3245055

[28] Vahl Davis GD. (1983), Natural convection of air in a square cavity: A bench mark numerical solution. International Journal for Numerical Methods in Fluids 3: 249-264. https://doi.org/10.1002/fld.1650030305

[29] Abdul Razak RK, Afzal A, Mohammed Samee AD, Ramis MK. (2019). Effect of cladding on thermal behavior of nuclear fuel element with non-uniform heat generation. Prog Nucl Energy 111: 1-14. https://doi.org/10.1016/j.pnucene.2018.10.013

[30] Afzal A, Samee ADM, Razak RKA, Ramis MK. (2019).
Steady and transient state analyses on conjugate laminar forced convection heat transfer. Arch Comput Methods Eng 2019: 1-36. https://doi.org/10.1007/s11831-01809303-x

[31] Abdul Razak RK, Afzal A, Mohammed Samee AD, Ramis MK. (2019). Investigation of dimensionless parameters and geometry effects on heat transfer characteristics of Liquid sodium flowing over a vertical flat plate. Heat Transf - Asian Res 48: 62-79. https://doi.org/10.1002/htj.21368

\section{NOMENCLATURE}

$A_{r} \quad$ aspect ratio of the plate

$b \quad$ half plate-to-plate spacing

$B$ dimensionless half plate-to-plate spacing

$H \quad$ height of the plate

$H_{\text {spot }} \quad$ Location of hot spot in solid

$K \quad$ thermal conductivity

$\ell_{0} \quad$ distance of the outflow boundary

$L_{o} \quad$ dimensionless distance of the outflow boundary

$N_{c c} \quad$ conduction-convection parameter

$N u_{H} \quad$ average Nusselt number

$\operatorname{Pr} \quad$ Prandtl number

$q^{\prime \prime \prime}(x) \quad$ volumetric energy generation function

$q_{\max }^{\prime \prime \prime} \quad$ maximum volumetric energy generation

$Q(X)$ dimensionless volumetric energy generation

$Q_{\max } \quad$ maximum volumetric energy generation

$Q_{t} \quad$ total energy generation parameter

$\operatorname{Re}_{H} \quad$ flow Reynolds number

$T$ temperature

$T_{o} \quad$ maximum allowable temperature in plate

$u \quad$ velocity component in axial direction

$U$ dimensionless velocity component in axial

$U_{\infty} \quad$ free stream velocity

$v \quad$ velocity component in transverse direction

$V \quad$ dimensionless velocity component in transverserse

$x \quad$ axial co-ordinate

$X \quad$ dimensionless axial co-ordinate

$y \quad$ transverse co-ordinate

$Y$ dimensionless transverse co-ordinate

$W \quad$ half of the thickness of the plate

\section{Greek symbols}

$\theta$ dimensionless temperature

$v \quad$ kinematic viscosity of the coolant

$\Psi \quad$ dimensionless stream function

$\Omega \quad$ dimensionless vorticity

\section{Subscripts}

$f \quad$ fluid domain

opt optimum

$s \quad$ solid domain

sf $\quad$ solid-fluid interface

$\infty \quad$ free stream

spot hotspots 